\title{
Clinical correlation between premature ovarian failure and a chromosomal anomaly in a 22-year-old Caucasian woman: a case report
}

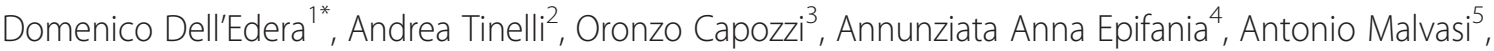 \\ Dominga Lofrese ${ }^{1}$, Elena Pacella ${ }^{6}$, Giusi Natalia Milazzo ${ }^{7}$, Eleonora Mazzone ${ }^{1}$, Manuela Leo ${ }^{1}$ and Mariano Rocchi ${ }^{3}$
}

\begin{abstract}
Introduction: Premature ovarian failure is defined as the cessation of ovarian activity before the age of 40 years. It is biochemically characterized by low levels of gonadal hormones (estrogens and inhibins) and high levels of gonadotropins (luteinizing hormone and follicle-stimulating hormone).

Case presentation: Our patient, a 22-year-old Caucasian woman under evaluation for infertility, had experienced secondary amenorrhea from the age of 18 . No positive family history was noted regarding premature menopause. An examination of our patient's karyotype showed the presence of a reciprocal translocation, apparently balanced, which had the $X$ chromosome long arm (q13) and the 14 chromosome short arm (p12) with consequent karyotype: 46, X, t(X; 14)(q13;p12).

Conclusions: Our study has underlined that karyotyping is one of the fundamental investigations in the evaluation of amenorrhea. It highlighted a genetic etiology, in the form of a chromosomal abnormality, as the causal factor in amenorrhea.
\end{abstract}

\section{Introduction}

Premature ovarian failure (POF) is defined by the cessation of ovarian activity before the age of 40 years [1]. This condition is biochemically characterized by low levels of gonadal hormones (estrogens and inhibins) and high levels of gonadotropins (luteinizing hormone $(\mathrm{LH})$ and follicle-stimulating hormone (FSH)) [2].

POF is considered idiopathic [3] in two thirds of cases, with the patient having a normal karyotype; in the remaining third of cases, it is secondary to genetic anomalies [4], autoimmune pathologies [5], pharmacological therapies [6], radiotherapy, or surgical oophorectomy.

In the absence of surgical oophorectomy, chemotherapy or pelvic radiation, POF encompasses a heterogeneous spectrum of conditions through two major mechanisms, follicle dysfunction and follicle depletion [7]. Although there are many other reasons for ovarian failure, genetic

\footnotetext{
* Correspondence: ducati98@libero.it

${ }^{1}$ Unit of Cytogenetic and Molecular Genetics, Madonna delle Grazie Hospital, Matera 75100 , Italy

Full list of author information is available at the end of the article
}

or chromosomal causes are the most important as their presence affects subsequent management.

Our study emphasizes that karyotyping is one of the fundamental investigations in the evaluation of amenorrhea. It highlights a genetic etiology, in the form of a chromosomal abnormality, as the causal factor in amenorrhea.

\section{Case presentation}

Our patient, a 22-year-old Caucasian woman under evaluation for infertility, had experienced secondary amenorrhea from the age of 18 years. She had received hormonal replacement for the past two years, which resulted in cyclical bleeding, but she remained anovulatory. No positive family history was noted regarding premature menopause.

Pelvic ultrasonography showed the presence of an anteflexed uterus, with a normal profile, echostructure and dimensions. Her endometrium had a normal echographic aspect. Both her right and left ovary were normal with respect to dimension and form, without any liquid effusion. A hysterosalpingogram confirmed the normal uterus-tubal anatomy. 
Magnetic resonance imaging of her encephalon and hypophysis using paramagnetic contrast showed that her sellar cavity had regular morphology and dimensions, without any structural alterations. The adenohypophysis was devoid of alterations. Her hypophyseal peduncle oriented normally. Serum anti-ovarian and anti-adrenal antibodies were absent. As it is possible to see from the Table 1, our patient had high levels of gonadotropins (LH: 41.17IU/L and FSH: 79.90IU/L; hypergonadotropic amenorrhea) [2]. Her thyroid-stimulating hormone, free tri-iodothyronine and free thyroxin hormone levels were normal, while the levels of anti-thyroid peroxidase antibodies and anti-thyroglobulin antibodies were very high.

It was necessary, at this point, to conclude the diagnostics by studying her karyotype. Her karyotype was obtained from $\mathrm{T}$ lymphocytes extracted from peripheral blood using the common culture technique. The obtained chromosomes were banded with Q-banding methods using quinacrine. An examination of her karyotype revealed the presence of a mutual translocation, apparently balanced, that involved the $\mathrm{X}$ chromosome long arm (q13) and the 14 chromosome short arm (p12), with consequent karyotype 46,X,t(X;14)(q13;p12) (Figure 1).

Breakpoints were confirmed with fluorescent in situ hybridization (Figure 2, Table 2). To evaluate the inactivation of the $\mathrm{X}$ chromosome, we used the human androgen receptor (HUMARA) assay, which uses the locus of the androgen receptor in $\mathrm{Xq11.2}$. In the first exon of the gene there was a highly polymorphic tri-nucleotide repetition (CAG) next to the cleavage sites of restriction enzymes sensitive to methylation (HpaII or HhaI), methylated only on the inactive $\mathrm{X}$ chromosome. The assay demonstrated that the active $\mathrm{X}$ chromosome was translocated (X-autosome: X; 14).
To assess whether this was a de novo or a segregating chromosomal abnormality, we studied the karyotype of both parents. Their karyotypes were normal, implying that the chromosomal abnormality was de novo. Furthermore, our patient did not present clinical manifestations associated with X-linked recessive diseases.

\section{Discussion}

$\mathrm{X}$-autosome translocations are extremely rare (one in $30,000)$. In women, one of the $\mathrm{X}$ chromosomes is inactive, and this inactivation is completely random. This phenomenon is called lyonization. In cases of $\mathrm{X}$ autosome translocation, the inactivation is not random but involves the none-translocated X chromosome $[9,10]$.

We must consider that the X-inactivation center in the $\mathrm{Xq13}$ area is turned off in the translocated chromosome, and different genes, which are important for the development and/or the functionality of the ovary, are present on the long arm of chromosome X [11].We can assume that $\mathrm{X}$-autosome translocations do not interrupt the genes involved in ovarian functionality, but that they cause altered expression, because of their 'position effect' [12].

In females with an active $\mathrm{X}$ chromosome translocated in all cells and with the breakpoint not interrupting any functional gene, about half have ovarian failure (breakpoints within the Xq13 to q26 region) and the other half have a normal phenotype (breakpoints outside the Xq13 to q26 region) [13-15].

\section{Conclusions}

The purpose of this therapy was not only to intervene in her climacteric symptoms, but to realize at the same time primary and/or secondary prevention of osteoporosis, cardiovascular pathology and cerebral involutional pathologies.

Table 1 Hormonal assays

\begin{tabular}{lll}
\hline Hormonal evaluation & Result & Normal range \\
\hline Thyroid-stimulating hormone $(\mathrm{m} / \mathrm{U} / \mathrm{mL})$ & 3.01 & 0.40 to 4.50 \\
Free tri-iodothyronine $(\mathrm{pg} / \mathrm{mL})$ & 4.21 & 2.30 to 5.10 \\
Free thyroxin $(\mathrm{ng} / \mathrm{dL})$ & 1.32 & 0.80 to 2.00 \\
Thyroglobulin $(\mathrm{ng} / \mathrm{mL})$ & $3.2^{\mathrm{a}}$ & $<25$ \\
Anti-thyroid peroxidase antibodies $(\mathrm{IU} / \mathrm{mL})$ & $172^{\mathrm{a}}$ & $<30$ \\
Anti- thyroglobulin antibodies $(\mathrm{IU} / \mathrm{mL})$ & $488^{\mathrm{a}}$ & $<50$ \\
Parathyroid hormone $(\mathrm{ng} / \mathrm{mL})$ & 32.42 & 9 to 72 \\
Follicle-stimulating hormone $(\mathrm{IU} / \mathrm{L})$ & $79.90^{\mathrm{a}}$ & $<30$ \\
Luteinizing hormone $(\mathrm{IU} / \mathrm{L})$ & $41.17^{\mathrm{a}}$ & $<9$ \\
17-beta-estradiol $(\mathrm{pg} / \mathrm{mL})$ & 9 & $<10$ \\
Prolactin $(\mathrm{ng} / \mathrm{mL})$ & 6.2 & $<20$ \\
Testosterone $(\mathrm{ng} / \mathrm{mL})$ & 0.22 & 0.1 to 1.0 \\
Testosterone-free $(\mathrm{pg} / \mathrm{mL})$ & 1.4 & 1.1 to 3.1 \\
\hline
\end{tabular}

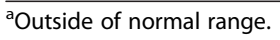




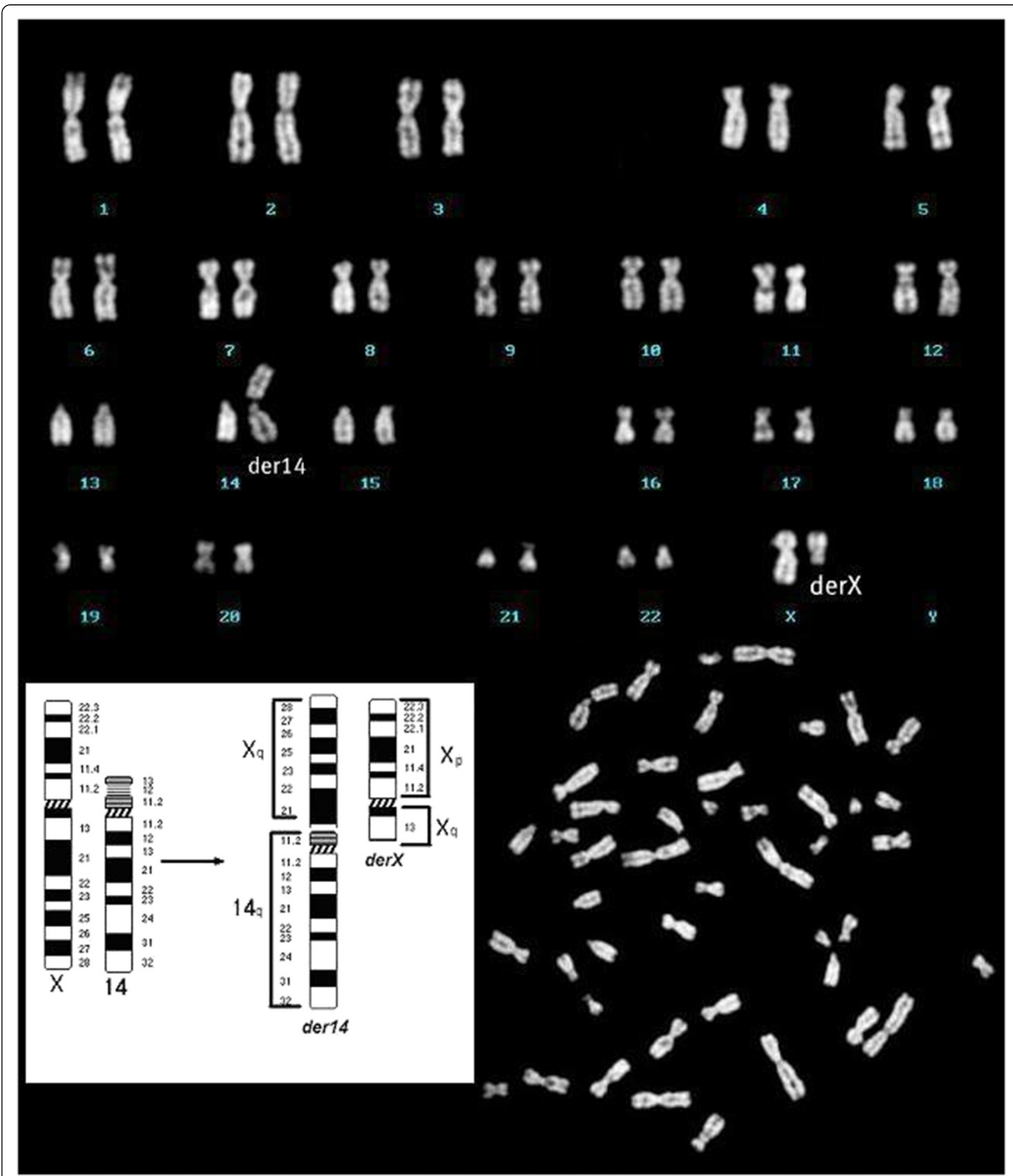

Figure 1 Karyotype $46, X, t(X ; 14)(q 13 ; p 12)$. 




Figure 2 BAC clones used for fluorescent in situ hybridization with the relative position on the $\mathrm{X}$ chromosome. In the two images you see the signs of the clones which define the breakpoint on X. Also see Table 2.

Our study has underlined that karyotyping is one of the fundamental investigations in the evaluation of amenorrhea. It has highlighted a genetic etiology for amenorrhea in the form of a chromosomal abnormality.

\section{Consent}

Written informed consent was obtained from the patient for publication of this case report and accompanying

Table 2 BAC clones used for fluorescent in situ hybridization with its location on the $\mathrm{X}$ chromosome

\begin{tabular}{lllc}
\hline Clone & Band & Position & FISH resolution \\
\hline RP11-450P7 & Xp11.1 & chrX:21,533,785-21,657,970 & derX \\
RP11-21E13 & Xp11.1 & chrX:57,294,374-57,500,705 & derX \\
RP11-63004 & Xq13.3 & chrX:73,819,700-73,985,772 & derX \\
RP11-91J20 & Xq13.3 & chrX:74,412,682-74,572,432 & derX \\
RP11-194N18 & Xq13.3 & chrX:75,606,737-75,754,256 & der14 \\
RP11-28L16 & Xq21.1 & chrX:76,249,350-76,405,210 & der14 \\
RP11-19G6 & Xq21.1 & chrX:77,789,620-77,954,427 & der14 \\
RP11-91G23 & Xq21.1 & chrX:79,149,705-79,309,977 & der14 \\
RP11-336F4 & Xq21.1 & chrX:83,463,633-83,463,726 & der14 \\
RP11-210111 & Xq21.31 & chrX:90,459,260-90,599,859 & der14 \\
RP11-138B3 & Xq22.1 & chrX:98,535,557-98,698,689 & der14 \\
RP11-265K3 & Xq28 & chrX:154,603,527-154,763,828 & der14 \\
\hline
\end{tabular}

The clones can be displayed on the site of the University of California, Santa Cruz [8]. FISH: fluorescent in situ hybridization. images. A copy of the written consent is available for review by the Editor-in-Chief of this journal.

\section{Competing interests}

The authors declare that they have no competing interests.

\section{Authors' contributions}

DD analyzed and interpreted the patient data and wrote the manuscript. AT, EM, GNM, AM and EP worked up the clinical details and helped to prepare the manuscript. $A A E, D L$ and $M L$ studied the androgen receptor gene. OC and MR performed the fluorescent in situ hybridization. All authors read and approved the final manuscript.

\section{Author details}

'Unit of Cytogenetic and Molecular Genetics, Madonna delle Grazie Hospital, Matera 75100, Italy. ${ }^{2}$ Obstetrics and Gynecology Department, V. Fazzi Hospital, Lecce, Italy. ${ }^{3}$ Department of Biology, University of Bari, Bari, Italy. ${ }^{4}$ Unit of Clinical Chemistry, Madonna delle Grazie Hospital, Matera, Italy. ${ }^{5}$ Obstetrics and Gynecology Department, Santa Maria Hospital, Bari, Italy. ${ }^{6}$ Department of Ophthalmology, Sapienza University, Rome, Italy. ${ }^{7}$ S'Andrea Hosptital, Sapienza University, Rome, Italy.

Received: 5 June 2012 Accepted: 20 September 2012 Published: 29 October 2012

\section{References}

1. Nelson LM: Clinical practice. Primary ovarian insufficiency. N Engl J Med 2009, 360(6):606-614.

2. Massin N, Meduri G, Bachelot A, Misrahi M, Kuttenn F, Touraine P: Evaluation of different markers of the ovarian reserve in patients presenting with premature ovarian failure. Mol Cell Endocrinol 2008, 282(1-2):95-100.

3. Massin N, Czernichow C, Thibaud E, Kuttenn F, Polak M, Touraine P: Idiopathic premature ovarian failure in 63 young women. Horm Res 2006, 65(2):89-95.

4. Aittomäki K, Lucena JL, Pakarinen P, Sistonen P, Tapanainen J, Gromoll J, Kaskikari R, Sankila EM, Lehväslaiho H, Engel AR, Nieschlag E, Huhtaniemi I, de la Chapelle A: Mutation in the follicle-stimulating hormone receptor 
gene causes hereditary hypergonadotropic ovarian failure. Cell 1995, 82(6):959-968.

5. Dragojević-Dikić S, Marisavljević D, Mitrović A, Dikić S, Jovanović T, JankovićRaznatović S: An immunological insight into premature ovarian failure (POF). Autoimmun Rev 2010, 9(11):771-774.

6. Bedaiwy MA, Abou-Setta AM, Desai N, Hurd W, Starks D, El-Nashar SA, Al-Inany HG, Falcone T: Gonadotropin-releasing hormone analog cotreatment for preservation of ovarian function during gonadotoxic chemotherapy: a systematic review and meta-analysis. Fertil Steril 2011, 95(3):906-914

7. Vujovic S: Aetiology of premature ovarian failure. Menopause Int 2009, 15(2):72-75.

8. Human (Homo sapiens) Genome Browser Gateway. http://genome.ucsc.edu/ cgi-bin/hgGateway?db=hg18.

9. Cottrell CE, Sommer A, Wenger GD, Bullard S, Busch T, Nash Krahn K, Lidral AC, Gastier-Foster JM: Atypical X-chromosome inactivation in an X;1 translocation patient demonstrating Xq28 functional disomy. Am J Med Genet A 2009, 149A(3):408-414.

10. Schmidt M, Du Sart D: Functional disomies of the $X$ chromosome influence the cell selection and hence the $X$ inactivation pattern in females with balanced $X$-autosome translocations: a review of 122 cases. Am J Med Genet 1992, 42(2):161-169.

11. Wolff $D J$, Schwartz $S$, Carrel L: Molecular determination of $X$ inactivation pattern correlates with phenotype in women with a structurally abnormal X chromosome. Genet Med 2000, 2(2):136-141.

12. Baronchelli S, Villa N, Redaelli S, Lissoni S, Saccheri F, Panzeri E, Conconi D, Bentivegna A, Crosti F, Sala E, Bertola F, Marozzi A, Pedicini A, Ventruto M, Police MA, Dalprà L: Investigating the role of $X$ chromosome breakpoints in premature ovarian failure. Mol Cyto Genet 2012, 5(1):32.

13. Layman L: Human gene mutations causing infertility. J Med Genet 2002, 39(3):153-161

14. Rizzolio F, Sala C, Alboresi S, Bione S, Gilli S, Goegan M, Pramparo T, Zuffardi $\mathrm{O}$, Toniolo D: Epigenetic control of the critical region for premature ovarian failure on autosomal genes translocated to the $\mathrm{X}$ chromosome: a hypothesis. Hum Genet 2007, 121(3-4):441-450.

15. Schlessinger D, Herrera L, Crisponi L, Mumm S, Percesepe A, Pellegrini M, Pilia G, Forabosco A: Genes and translocations involved in POF. Am J Med Genet 2002, 111(3):328-333.

doi:10.1186/1752-1947-6-368

Cite this article as: Dell'Edera et al: Clinical correlation between premature ovarian failure and a chromosomal anomaly in a 22-year-old Caucasian woman: a case report. Journal of Medical Case Reports 2012 6:368.

\section{Submit your next manuscript to BioMed Central and take full advantage of:}

- Convenient online submission

- Thorough peer review

- No space constraints or color figure charges

- Immediate publication on acceptance

- Inclusion in PubMed, CAS, Scopus and Google Scholar

- Research which is freely available for redistribution 